\title{
Beta Catenin Measurement
}

National Cancer Institute

\section{Source}

National Cancer Institute. Beta Catenin Measurement. NCI Thesaurus. Code C103357.

The determination of the amount of the beta catenin in a sample. 